\title{
Rescuing Immunosenescence via Non-Specific Vaccination
}

\author{
Alexander I. Mosa 1,2 \\ 1 Institute of Medical Sciences, University of Toronto, Toronto, ON M5T 1P8, Canada; \\ alexander.mosa@uhnresearch.ca \\ 2 Toronto General Hospital, University Health Network, Toronto, ON M5G 2A2, Canada
}

\begin{abstract}
Discrepancies in lifespan and healthy-life span are predisposing populations to an increasing burden of age-related disease. Accumulating evidence implicates aging of the immune system, termed immunosenescence, in the pathogenesis of multiple age-related diseases. Moreover, immune dysregulation in the elderly increases vulnerability to infection and dampens pathogenspecific immune responses following vaccination. The health challenges manifesting from these age related deficits have been dramatically exemplified by the current SARS-CoV-2 pandemic. Approaches to either attenuate or reverse functional markers of immunosenescence are therefore urgently needed. Recent evidence suggests systemic immunomodulation via non-specific vaccination with live-attenuated vaccines may be a promising avenue to at least reduce aged population vulnerability to viral infection. This short review describes current understanding of immunosenescence, the historical and mechanistic basis of vaccine-mediated immunomodulation, and the outstanding questions and challenges required for broad adoption.
\end{abstract}

Keywords: non-specific vaccination; BCG; SARS-CoV-2

check for

updates

Citation: Mosa, A.I. Rescuing Immunosenescence via Non-Specific Vaccination. Immuno 2021, 1, 231-239. https://doi.org/10.3390/

immuno1030015

Academic Editor: Mauro Vaccarezza

Received: 21 April 2021

Accepted: 22 July 2021

Published: 27 July 2021

Publisher's Note: MDPI stays neutral with regard to jurisdictional claims in published maps and institutional affiliations.

Copyright: (C) 2021 by the author. Licensee MDPI, Basel, Switzerland. This article is an open access article distributed under the terms and conditions of the Creative Commons Attribution (CC BY) license (https:/ / creativecommons.org/licenses/by/ $4.0 /)$.

\section{Introduction}

Life expectancy is outpacing healthy-life expectancy in developed nations [1]. Increased lifespan without a concomitant increase in health span is partly attributable to immunosenescence, a phenomena characterized by a progressive reduction in circulating PBMCs and basal elevations in pro inflammatory cytokines, manifesting as increased vulnerability to infection, reduced immunosurveillance, impaired proteostasis, and activation of latent viruses [1,2]. Attenuating age-related immune dysregulation is therefore an urgent public health priority, with recent initiatives focusing on the potential of adjuvantation and non-specific vaccination to resuscitate immune function [3,4].

These efforts have assumed newfound urgency with the SARS-CoV-2's expected progression to endemicity and the need to elicit durable, protective immune responses among the elderly [4]. However, deficits in adaptive immune responses following vaccination only partially describe the challenge of immunosenescence, with accompanying dysfunction in innate immunity aggregating in systemic, refractory inflammation termed "inflammageing", which may increase susceptibility to multiple age-related diseases with convergent inflammatory pathogenesis, such as diabetes, atherosclerosis, and cancer [5].

Indeed, accumulating evidence implicating elevated circulating pro-inflammatory cytokines in both cognitive decline and frailty suggests targeting age-related immune dysfunction may be a prerequisite to attenuating age-related pathologies [6]. Given the unsustainable costs of managing individual comorbidities in aging populations, and the challenge of establishing robust clinical infrastructures capable of maintaining the linkageto-care required for these complex populations, targeted approaches to reduce age-related disease are both public and private research priorities [7].

Recent trials recommend low-cost interventions, unencumbered by the need for lengthy development cycles, such as the BCG vaccine, as promising candidates for rescuing, or at least partly mitigating, immunosenescence (Figure 1) [8]. This review summarizes the 
historical background of non-specific vaccination in vulnerable populations, explores the putative mechanisms of immunomodulation associated with these vaccines, and describes their promise in the context of recent clinical trials. Though immunomodulation in the elderly is a nascent field, with few randomized controlled trials explicitly evaluating the potential of non-specific vaccination, this review surveys existing epidemiological data, largely in pediatric populations, coupled with preclinical studies using candidate non-specific vaccines, to contextualize recent clinical results in geriatric populations and advocate for renewed efforts in evaluating if scalable, vaccine-based interventions can rescue immunosenescence.

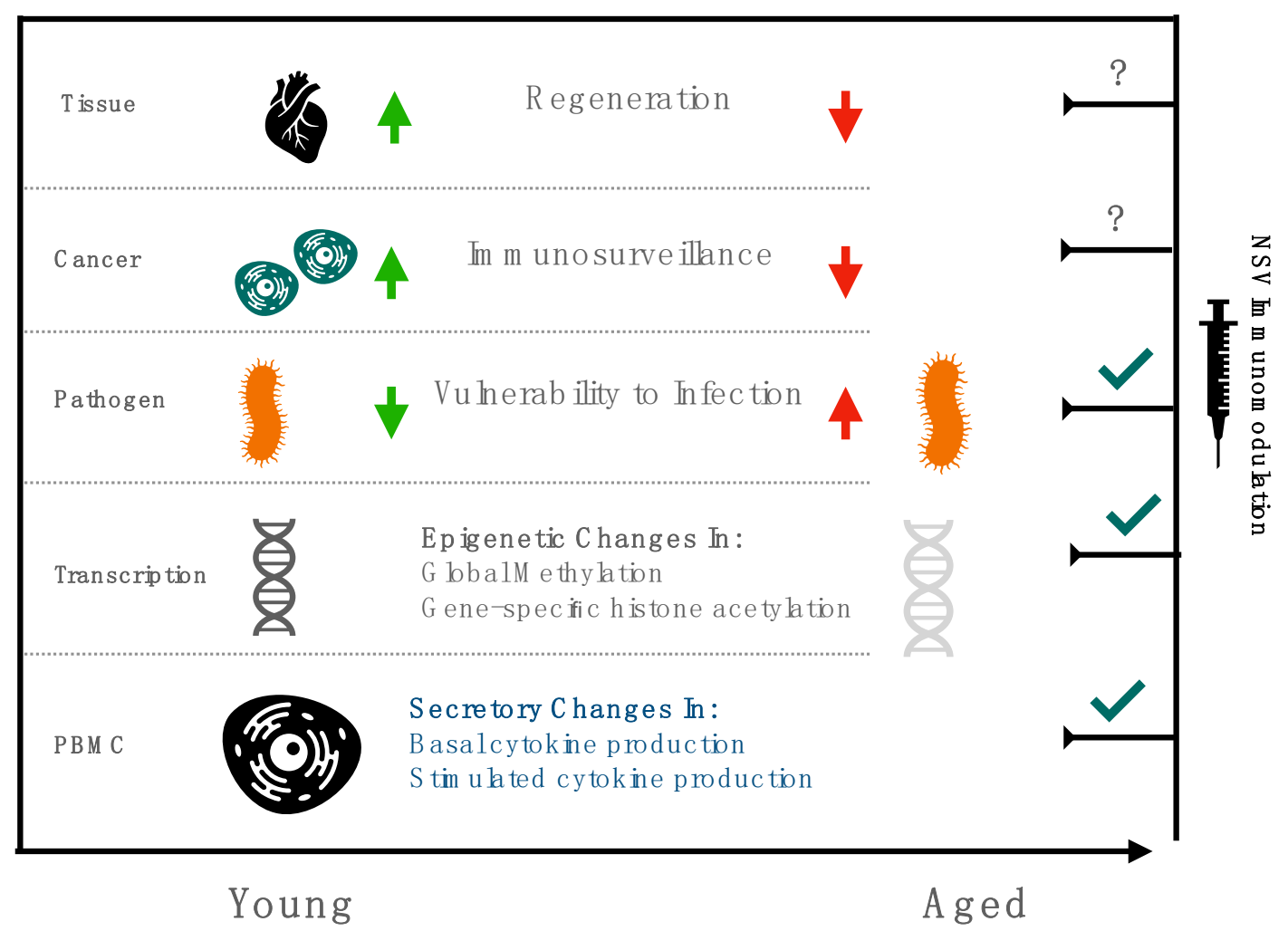

Figure 1. Markers of immunosenescence targeted for immunomodulation by non-specific vaccination. Figure was made using keynote $[5,6]$.

\section{History of Non-Specific Vaccination}

Non-specific effects (NSE) following vaccination have been widely reported, with epidemiological observations suggesting reductions in morbidity and mortality following vaccination exceeding the disease burden associated with those pathogens (tuberculosis, measles, polio) in unvaccinated populations [9]. For example, the BCG vaccination is associated with a significant reduction in all-cause mortality $(\sim 50 \%)$ in certain populations, which far exceeds the reductions in mortality that can be attributed to prevention of tuberculosis alone [10]. That these reductions are immune mediated is supported by the improved neonatal survival following BCG vaccination attributed to lower rates of sepsis and severe respiratory infection [11]. Though reductions in mortality observed following BCG vaccination in low-birth-weight Guinean neonates do not uniformly obtain significance, subgroup analysis indicates a significant decrease in infectious disease mortality [12].

Reduced morbidity has also been observed, with populations of both BCG-vaccinated children and adults at a lower risk of acute respiratory tract infections $[9,13]$. Recent analysis using a composite outcome of COVID-19 related mortality suggests a $10.4 \%$ reduction for every $10 \%$ increase in the population-wide BCG index, an estimation of country-specific BCG vaccination coverage [14]. Supporting this finding, a separate analysis observed reduced COVID-19 disease burden among countries with universal BCG vaccination [15]. 
Data pooled from international health surveys to include a cohort of $>100,000$ children from 19 countries additionally found BCG vaccination to be associated with a $17-37 \%$ risk reduction for undefined acute lower respiratory infection [16]. However, despite adjustments, the possibility of unaccounted confounders in non-randomized conditions limits unambiguous conclusions from these observational studies. Baseline confounding, characterized by reduced vaccination of frail children, may bias results toward a protective, non-specific effect [17]. This possibility may be aggravated by later age of vaccination for frail children, especially because two cohort studies reported that the protective non-specific effects of BCG vaccination decrease with age [11,12]. However, in a separate study adjusting for frailty, the main observations of protective NSE following BCG vaccination were unaltered [18]. These concerns are further mitigated by the observation of protective NSE following multiple live-attenuated vaccines, including the BCG, oral-polio, and measles vaccines [19].

Early, seminal observations of NSE of live attenuated vaccines followed the introduction of the measles vaccination to Guinea-Bissau [20]. The data suggested at least a 50\% reduction in mortality among vaccinated children aged 6 to 35 months, which is exceeds the measles specific mortality $[13,21]$. Further, vaccination with any additional dose was found to reduce mortality, with subgroup analysis revealing a sex-differential effect in favor of girls, a trend also observed in a pediatric Senegalese population [19,22]. Similar findings of sex-specific effects in favor of girls have also been obtained following BCG vaccination [23].

Measles vaccination is also associated with protective NSE in high-income settings [24,25]. Specifically, in a Roman pediatric cohort, vaccination was protective against unspecified infectious disease ( $\mathrm{HR}=0.29 ; 95 \% \mathrm{CI}$ : $0.25-0.34)$ [26]. Consistent with protective NSE following BCG observed in epidemiological analysis of COVID-19 mortality and BCG index, heightened protection was observed against respiratory infection (HR: 0.18; 95\% CI: 0.07 to 0.48 [26]. Measles vaccination was also protective in a pediatric Danish cohort, with on-time MMR vaccination associated with a $10 \%$ reduction in risk of infection-related hospital admission, with a needed number to vaccinate of 201 (95\% CI: 159-272) [27]. More recent analysis indicates that these reductions may not be attributable to NSE, but rather to the immunosuppressive effects of measles infection, which may increase vulnerability to subsequent infections [28]. These findings suggest MV is not reducing mortality by NSE, including heterologous immunity, but is reducing undercounted measles-related morbidity - which would be consistent with a measles-specific protective mechanism [29]. Interpreting reductions in child mortality following $\mathrm{MV}$, even in randomized settings, such as the more recent 2010 trial in Guinea-Bissau, which additionally observed reduced incidence of infection requiring hospitalization, is therefore complicated by measles specific virology [30].

Protective NSE following live, attenuated vaccination were also observed following vaccination with the oral polio vaccine (OPV) in Guinea-Bissau [31]. Intriguingly, evidence of dose-specific effects was observed in pooled analysis of seven randomized trials, with boys benefitting from a 13\% reduction in mortality with each additional OPV dose administered [32]. Additional studies supporting protective NSE of OPV, including a randomized controlled trial in Bangladesh, found reduced incidence of diarrhea periods among those vaccinated with the live OPV relative to the inactivated (IPV) [33]. Along with a separate Finnish study comparing OPV to IPV, which found a protective effect against ear infections, these findings suggest the protective effect of OPV is greater than its polio-specific reductions in morbidity [34].

\section{Proposed Mechanisms of Immunomodulation}

Hypothesized mechanisms for the protective NSE of live attenuated vaccines include induction of (i) heterologous immunity, and (ii) trained immunity $[4,10,12]$. The former refers to cross-reactive cellular responses manifesting from the antigenic convergence of pathogen epitopes [35]. In this respect, heterologous immunity is not a generalized NSE 
per se, but rather a phenomenon emergent from antigenic convergence, which is restricted only to epitopes cross-reactive between the vaccine and challenge pathogen. Though clinically relevant, this phenomenon does not constitute a form of immunomodulation and is unrelated to any systemic activation of the immune system to increase resilience to infection, even though it may afford robust protection to individual cross-reacting pathogens. In contrast, trained immunity, which is characterized by a vigorous, unqualified innate response following infection, and is unrelated to the infecting pathogen, may constitute the kind of systemic immunomodulation with the potential to rescue immunosenescence (Figure 2) [36]. Indeed, epidemiological data to date have not resolved the relative contributions of heterologous or trained immunity to the observed NSE of vaccination, though an analysis of epitope cross-reactivity between immunogens and common pathogens could help to elucidate these dynamics.

Initial studies investigating the role of trained immunity following BCG vaccination controlled for heterologous immunity by employing lymphocytic-deficient animal models, such as severe combined immunodeficiency mice [37]. Remarkably, following challenge with Candida albicans, $100 \%$ of BCG vaccinated mice survived, compared to only $30 \%$ of challenged controls [24]. Further, $>1 \log$ reductions in C. albicans colony-forming units were observed in the kidney, the target of disseminated candidiasis in mice, indicating direct control of fungal burden by trained monocytes [37]. Functionally, these NSE were attributed to increase pro-inflammatory cytokine production, including TNF, IFN-gamma, and IL-1 $\beta$ following challenge, an effect also observed among the stimulated PBMC of healthy human volunteers [37]. Importantly, increased cytokine production was observed in response to unrelated bacterial and fungal pathogens without evidence of antigenic convergence, indicating a genuine NSE following vaccination $[37,38]$. Accompanying these heterologous effects were increased expression of known cell surface markers of activation in monocytes, including CD11b and Toll-like receptor 4 (TLR4). The durability of this trained immunity, which lasted at least three months and included both phenotypic markers of activation in circulating monocytes and increased inflammatory cytokine production, may be owing to epigenetic modification induced by BCG vaccination, with experimental blocking of histone methylation largely abrogating the training induced by BCG vaccination [37]. In particular, NOD2 dependent histone 3 lysine 4 trimethylation (H3K4me3) was observed and shown to be required for induction of heterologous effects following BCG vaccination.

Substantiating preclinical data, direct observation of protective NSE of BCG in humans, was afforded via challenge with the live attenuated yellow fever vaccine (YFV), which allowed for a safe, controlled human infection trial [39]. In this study, BCG vaccination was associated with a reduced peak viremia following YFV challenge, as measured by CT values, which was again correlated to increased production of the pro-inflammatory cytokines IL-1 $\beta$ and IL-6 [25]. Intriguingly, increased CT values were not correlated with specific cellular responses, including IFN-gamma production. Consistent with data obtained in preclinical murine models, reduced viremia following BCG vaccination was associated with epigenetic modification, including histone 3 lysine 27 acetylation (H3K27ac), a marker of active transcription $[39,40]$. BCG vaccination induced H3K27ac in several signaling pathways, including the phosphatidylinositol 3-kinase pathway, which was previously implicated in regulation of BCG-induced trained immunity [41]. Translationally, these observations are important in their discrimination of a "responder" and "non-responder" phenotype following BCG vaccination, which were partly modulated by polymorphisms in the IL1B promoter (rs16944) [42]. Trained immunity associated cytokine production was significantly impaired among homozygous carriers of the A allele in rs16944. Polymorphisms notwithstanding, the YFV challenge trial supported mechanisms of trained immunity consistent with both epidemiological studies and preclinical models, observing NSE related to epigenetic modifications in monocytes, including H3K4/K9 methylation and H3K27 acetylation, suggesting a mechanistic link between live, attenuated vaccination and durable, non-specific immunomodulation via long-term changes in transcriptional regulation [39]. 
Supporting phenotypic changes in monocytes as a NSE of vaccination, BCG vaccination induced a PBMC shift to a pro-inflammatory, M1-like phenotype metabolically characterized by increased glycolysis [43]. Glycolytic rate, as measured by glucose consumption, was nearly two-fold higher in monocytes primed with BCG. Akt and mTOR phosphorylation, driving glucose and glutamine metabolism, were at least partially responsible for mediating BCG-induced trained immunity in vitro [44]. Histone 3 trimethylation of lysine 4 was found to be increased at the mTOR promotor, providing a mechanistic link to the durability of the metabolic shift observed in trained immunity consistent with the epigenetic mechanisms observed for proinflammatory cytokine production [44,45]. Crucially, inhibition of BCG induced trained immunity with metabolic inhibitors of glutamine metabolism or glycolysis (rapamycin) impaired epigenetic modifications at the promotor sites of inflammatory cytokines, suggesting an epigenetic and metabolic changes are mutually inducing and must be choreographed for induction of trained immunity [43-46].

Though the precise mechanism of epigenetic-mediated trained immunity is still being resolved, evidence suggests hematopoietic stem and progenitor cells (HSPCs) are implicated in the longevity of the trained immune state [47]. Indeed, the NSE of BCG may be operative in bone marrow in originating PBMCs with the trained-epigenetic phenotype. Though tentative, epigenetic reprogramming of HSPCs is consistent with the duration of NSE following MV, OPV, and BCG vaccination, as previously observed $[9,11,13]$.

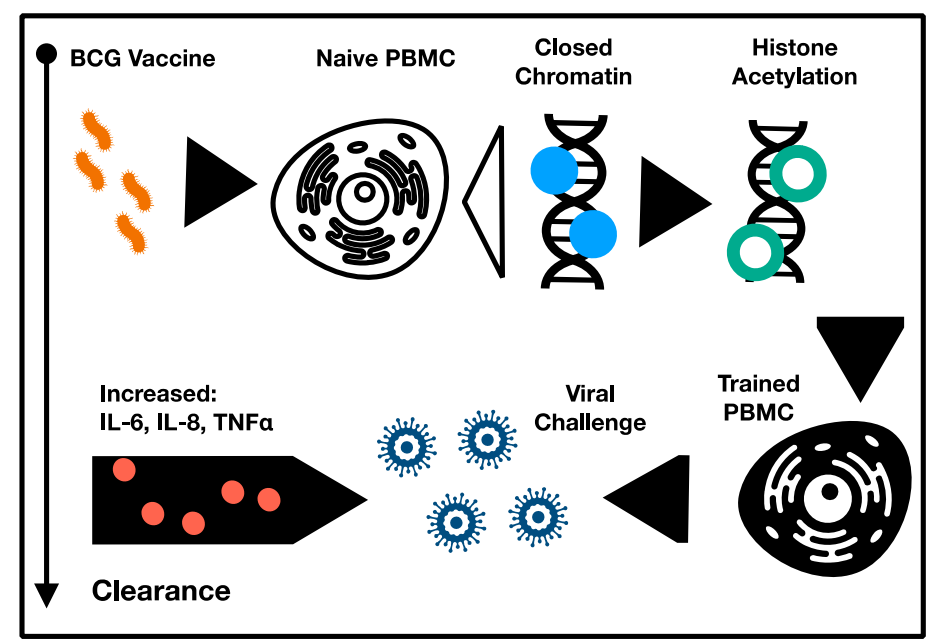

Figure 2. Epigenetic remodeling following non-specific vaccination aggregates in increased production of pro-inflammatory cytokines during viral challenge. Figure was made using keynote [25,39-41].

\section{Recent Clinical Trials}

Recently, the protective NSE of BCG vaccination observed in child populations have been translated to elderly populations to intentionally induce trained immunity, rather than provide specific protection from the vaccine's cognate antigen [48-50]. Following the success of earlier studies in Indonesia and Japan, which found evidence of non-specific protection from respiratory infections following BCG vaccination of elderly subjects, the ACTIVATE trial was initialized to evaluate the effect of a single BCG dose on 12-month incidence of respiratory infection in a hospitalized elderly cohort at high risk of respiratory infection with complications $[48,49,51]$.

Owing to the SARS-CoV-2 pandemic, to which the studied population was at heightened vulnerability, an interim analysis was performed to determine if BCG vaccination afforded non-specific protection from respiratory infection among the elderly. The authors observed significantly increased time to first infection, and a decreased incidence of new infections of probable viral origin (HR 0.21, $p=0.013$ ) [51]. Encouragingly, the correlates of protection were consistent with the mechanisms proposed in preclinical models, including increase pro-inflammatory cytokine production in stimulated PBMC, and evidence 
of epigenetic reprogramming (histone acetylation) at genes encoding pro-inflammatory cytokines (IL-6, TNFa) [37,51]. These findings suggest non-specific vaccination can rescue clinical deficits in immune function related to vulnerability to infection, but they cannot elucidate if these NSE are operative on other aspects of immunosenescence, such as decreased phagocytosis and increased basal production of pro inflammatory cytokines $[52,53]$. Accompanying these functional analyses, markers of immunosenescence identified via immune profiling of stimulated PBMC, such as MCP3, ENA78, IL7, ICAM1, and VCAM1, can be investigated to explore the broader shifts in immunobiography induced by BCG vaccination in the elderly [54].

Non-infection models, such as scratch tests to evaluate tissue regeneration, and exosome analysis, should also be incorporated into the systemic characterization of BCG's effect in immunosenescence [55]. With 22 registered clinical trials exploring the protective effects of BCG on SARS-CoV2 ongoing, samples to evaluate these changes in a randomized setting will be available across age cohorts for the first time [56].

\section{Conclusions and Perspectives}

Though initial evidence of the protective NSE of vaccines was derived from epidemiological studies, recent randomized controlled trials have yielded results indicating a pathogen agnostic protective effect and found immunological mechanisms consistent with preclinical models. Overestimation of the NSE of vaccination, particularly given the potential of infection with a vaccines cognate pathogen to induce systemic immune dysregulation, is a possibility that may temper interpretation of epidemiological data. However, at least in the case of BCG, where robust clinical data supported by ex vivo immunological analysis strongly implies a protective NSE following vaccination, further research into the durability, tolerability, in terms of the number of doses that can be safely and effective administered, and systemic effects on immunosenescence warrant further investigation and support by funding bodies. Given the high probability of a future pandemic, and the risk that vaccine development may be either unsuccessful or delayed relative to the SARS-CoV-2 experience, exploration of the potential of non-specific immunomodulation to increase population-level resilience to infection is a critical, unmet need.

Moderating the potential of non-specific vaccination for improving immune function in aged cohorts is a practical clinical challenge, and it includes the risk of eliciting autoantibodies, aggravating existing comorbidities with acute-inflammation, and elucidating intra-cohort variability. Equally challenging are the outstanding questions regarding the durability of trained immunity, and if intermittent boosting heightens the risk of side effects, including autoimmunity, which may be a rare yet persistent manifestations in certain vulnerable populations.

Future work may evaluate if, given these outstanding difficulties in repurposing existing vaccines, dedicated immunomodulators are viable candidates for drug development, or if a family of immunizations, each targeting discrete aspects of immunosenescence, is a feasible objective. Lastly, in the short-term, expanded clinical trials, and the establishment of a regulatory framework for the approval of NSV, are needed to translate the promise of trained immunity to vulnerable populations.

Funding: This research received no external funding.

Conflicts of Interest: The author declares no conflict of interest.

\section{References}

1. Salomon, J.A.; Wang, H.; Freeman, M.K.; Vos, T.; Flaxman, A.D.; Lopez, A.D.; Murray, C.J. Healthy life expectancy for 187 countries, 1990-2010: A systematic analysis for the Global Burden Disease Study 2010. Lancet 2012, 380, 2144-2162. [CrossRef]

2. Zhang, H.; Puleston, D.J.; Simon, A.K. Autophagy and Immune Senescence. Trends Mol. Med. 2016, 22, 671-686. [CrossRef]

3. Mannick, J.B.; Morris, M.; Hockey, H.-U.P.; Roma, G.; Beibel, M.; Kulmatycki, K.; Watkins, M.; Shavlakadze, T.; Zhou, W.; Quinn, D.; et al. TORC1 inhibition enhances immune function and reduces infections in the elderly. Sci. Transl. Med. 2018, 10, eaaq1564. [CrossRef] 
4. Bulut, O.; Kilic, G.; Domínguez-Andrés, J.; Netea, M.G. Overcoming immune dysfunction in the elderly: Trained immunity as a novel approach. Int. Immunol. 2020, 32, 741-753. [CrossRef] [PubMed]

5. Ferrucci, L.; Fabbri, E. Inflammageing: Chronic inflammation in ageing, cardiovascular disease, and frailty. Nat. Rev. Cardiol. 2018, 15, 505-522. [CrossRef] [PubMed]

6. Furman, D.; Campisi, J.; Verdin, E.; Carrera-Bastos, P.; Targ, S.; Franceschi, C.; Ferrucci, L.; Gilroy, D.W.; Fasano, A.; Miller, G.W.; et al. Chronic inflammation in the etiology of disease across the life span. Nat. Med. 2019, 25, 1822-1832. [CrossRef] [PubMed]

7. Piskovatska, V.; Stefanyshyn, N.; Storey, K.B.; Vaiserman, A.M.; Lushchak, O. Metformin as a geroprotector: Experimental and clinical evidence. Biogerontology 2018, 20, 33-48. [CrossRef]

8. Netea, M.G.; Giamarellos-Bourboulis, E.J.; Domínguez-Andrés, J.; Curtis, N.; Van Crevel, R.; van de Veerdonk, F.; Bonten, M. Trained Immunity: A Tool for Reducing Susceptibility to and the Severity of SARS-CoV-2 Infection. Cell 2020, 181, 969-977. [CrossRef]

9. Prentice, S.; Nassanga, B.; Webb, E.L.; Akello, F.; Kiwudhu, F.; Akurut, H.; Elliott, A.M.; Arts, R.J.; Netea, M.G.; Dockrell, H.M.; et al. BCG-Induced Non-Specific Effects on Heterologous Infectious Disease in Ugandan Neonates: An Investigator-Blind Randomised Controlled Trial. Lancet Infect. Dis. 2021, 21, 993-1003. [CrossRef]

10. Pollard, A.J.; Finn, A.; Curtis, N. Non-specific effects of vaccines: Plausible and potentially important, but implications uncertain. Arch. Dis. Child. 2017, 102, 1077-1081. [CrossRef]

11. Aaby, P.; Roth, A.; Ravn, H.; Napirna, B.M.; Rodrigues, A.; Lisse, I.M.; Stensballe, L.G.; Diness, B.R.; Lausch, K.R.; Lund, N.; et al. Randomized Trial of BCG Vaccination at Birth to Low-Birth-Weight Children: Beneficial Nonspecific Effects in the Neonatal Period? J. Infect. Dis. 2011, 204, 245-252. [CrossRef] [PubMed]

12. Biering-Sørensen, S.; Aaby, P.; Lund, N.; Monteiro, I.; Jensen, K.J.; Eriksen, H.B.; Schaltz Buchholzer, F.; Jørgensen, A.S.P.; Rodrigues, A.; Fisker, A.B.; et al. Early BCG-Denmark and neonatal mortality among infants weighing <2500 g: A randomized controlled trial. Clin. Infect. Dis. 2017, 65, 1183-1190. [CrossRef]

13. Blok, B.A.; Arts, R.J.W.; Van Crevel, R.; Benn, C.S.; Netea, M.G. Trained innate immunity as underlying mechanism for the long-term, nonspecific effects of vaccines. J. Leukoc. Biol. 2015, 98, 347-356. [CrossRef] [PubMed]

14. Escobar, L.E.; Molina-Cruz, A.; Barillas-Mury, C. BCG vaccine protection from severe coronavirus disease 2019 (COVID-19). Proc. Natl. Acad. Sci. USA 2020, 117, 17720-17726. [CrossRef]

15. Yitbarek, K.; Abraham, G.; Girma, T.; Tilahun, T.; Woldie, M. The effect of Bacillus Calmette-Guérin (BCG) vaccination in preventing severe infectious respiratory diseases other than TB: Implications for the COVID-19 pandemic. Vaccine 2020, 38, 6374-6380. [CrossRef]

16. Hollm-Delgado, M.-G.; Stuart, E.; Black, R.E. Acute Lower Respiratory Infection Among Bacille Calmette-Guérin (BCG)Vaccinated Children. Pediatrics 2013, 133, e73-e81. [CrossRef] [PubMed]

17. Higgins, J.P.T.; Soares-Weiser, K.; López, J.; Kakourou, A.; Chaplin, K.; Christensen, H.; Martin, N.K.; Sterne, J.; Reingold, A.L. Association of BCG, DTP, and measles containing vaccines with childhood mortality: Systematic review. BMJ 2016, 355 , i5170. [CrossRef]

18. Thysen, S.M.; Benn, C.S.; Gomes, V.F.; Rudolf, F.; Wejse, C.; Roth, A.; Kallestrup, P.; Aaby, P.; Fisker, A. Neonatal BCG vaccination and child survival in TB-exposed and TB-unexposed children: A prospective cohort study. BMJ Open 2020, 10, e035595. [CrossRef]

19. De Bree, L.C.J.; Koeken, V.A.C.M.; Joosten, L.A.B.; Aaby, P.; Benn, C.S.; van Crevel, R.; Netea, M.G. Non-specific effects of vaccines: Current evidence and potential implications. Semin. Immunol. 2018, 39, 35-43. [CrossRef]

20. Aaby, P.; Bukh, J.; Lisse, I.M.; Smits, A.J. Measles vaccination and reduction in child mortality: A community study from Guinea-Bissau. J. Infect. 1984, 8, 13-21. [CrossRef]

21. Aaby, P.; Samb, B.; Simondon, F.; Seck, A.M.C.; Knudsen, K.; Whittle, H. Non-specific beneficial effect of measles immunisation: Analysis of mortality studies from developing countries. BMJ 1995, 311, 481-485. [CrossRef] [PubMed]

22. Aaby, P.; Samb, B.; Simondon, F.; Knudsen, K.; Seck, A.M.C.; Bennett, J.; Whittle, H. Divergent Mortality for Male and Female Recipients of Low-Titer and High-Titer Measles Vaccines in Rural Senegal. Am. J. Epidemiol. 1993, 138, 746-755. [CrossRef] [PubMed]

23. Stensballe, L.G.; Nante, E.; Jensen, I.P.; Kofoed, P.-E.; Poulsen, A.; Jensen, H.; Newport, M.; Marchant, A.; Aaby, P. Acute lower respiratory tract infections and respiratory syncytial virus in infants in Guinea-Bissau: A beneficial effect of BCG vaccination for girls: Community based case-control study. Vaccine 2005, 23, 1251-1257. [CrossRef]

24. Tielemans, S.M.; de Melker, H.E.; Hahné, S.J.; Boef, A.G.; van der Klis, F.R.; Sanders, E.A.; Van Der Sande, M.A.; Knol, M.J. Non-specific effects of measles, mumps, and rubella (MMR) vaccination in high income setting: Population based cohort study in the Netherlands. BMJ 2017, 358, j3862. [CrossRef] [PubMed]

25. Bardenheier, B.H.; McNeil, M.; Wodi, A.P.; McNicholl, J.M.; DeStefano, F. Risk of Nontargeted Infectious Disease Hospitalizations Among US Children Following Inactivated and Live Vaccines, 2005-2014. Clin. Infect. Dis. 2017, 65, 729-737. [CrossRef] [PubMed]

26. La Torre, G.; Saulle, R.; Unim, B.; Meggiolaro, A.; Barbato, A.; Mannocci, A.; Spadea, A. The effectiveness of measles-mumpsrubella (MMR) vaccination in the prevention of pediatric hospitalizations for targeted and untargeted infections: A retrospective cohort study. Hum. Vaccines Immunother. 2017, 13, 1879-1883. [CrossRef] [PubMed]

27. Sørup, S.; Benn, C.S.; Poulsen, A.; Krause, T.G.; Aaby, P.; Ravn, H. Live Vaccine Against Measles, Mumps, and Rubella and the Risk of Hospital Admissions for Nontargeted Infections. JAMA 2014, 311, 826-835. [CrossRef] 
28. Mina, M.J.; Metcalf, C.J.E.; De Swart, R.L.; Osterhaus, A.D.M.E.; Grenfell, B.T. Long-term measles-induced immunomodulation increases overall childhood infectious disease mortality. Science 2015, 348, 694-699. [CrossRef]

29. Mina, M.J.; Kula, T.; Leng, Y.; Li, M.; De Vries, R.D.; Knip, M.; Siljander, H.; Rewers, M.; Choy, D.F.; Wilson, M.S.; et al. Measles virus infection diminishes preexisting antibodies that offer protection from other pathogens. Science 2019, 366, 599-606. [CrossRef]

30. Aaby, P.; Martins, C.L.; Garly, M.-L.; Balé, C.; Andersen, A.; Rodrigues, A.; Ravn, H.; Lisse, I.M.; Benn, C.S.; Whittle, H.C. Non-specific effects of standard measles vaccine at 4.5 and 9 months of age on childhood mortality: Randomised controlled trial. BMJ 2010, 341, c6495. [CrossRef]

31. Lund, N.; Andersen, A.; Hansen, A.S.K.; Jepsen, F.S.; Barbosa, A.; Biering-Sørensen, S.; Rodrigues, A.; Ravn, H.; Aaby, P.; Benn, C.S. The Effect of Oral Polio Vaccine at Birth on Infant Mortality: A Randomized Trial. Clin. Infect. Dis. 2015, 61, 1504-1511. [CrossRef]

32. Andersen, A.; Fisker, A.; Rodrigues, A.; Martins, C.; Ravn, H.; Lund, N.; Biering-Sørensen, S.; Benn, C.S.; Aaby, P. National Immunization Campaigns with Oral Polio Vaccine Reduce All-Cause Mortality: A Natural Experiment within Seven Randomized Trials. Front. Public Health 2018, 6, 13. [CrossRef] [PubMed]

33. Upfill-Brown, A.; Taniuchi, M.; Platts-Mills, J.A.; Kirkpatrick, B.; Burgess, S.L.; Oberste, M.S.; Weldon, W.; Houpt, E.; Haque, R.; Zaman, K.; et al. Nonspecific Effects of Oral Polio Vaccine on Diarrheal Burden and Etiology Among Bangladeshi Infants. Clin. Infect. Dis. 2017, 65, 414-419. [CrossRef] [PubMed]

34. Seppälä, E.; Viskari, H.; Hoppu, S.; Honkanen, H.; Huhtala, H.; Simell, O.; Ilonen, J.; Knip, M.; Hyöty, H. Viral interference induced by live attenuated virus vaccine (OPV) can prevent otitis media. Vaccine 2011, 29, 8615-8618. [CrossRef] [PubMed]

35. Agrawal, B. Heterologous Immunity: Role in Natural and Vaccine-Induced Resistance to Infections. Front. Immunol. 2019, 10, 2631. [CrossRef] [PubMed]

36. Netea, M.G.; Quintin, J.; Van Der Meer, J.W. Trained Immunity: A Memory for Innate Host Defense. Cell Host Microbe 2011, 9 , 355-361. [CrossRef]

37. Kleinnijenhuis, J.; Quintin, J.; Preijers, F.; Joosten, L.A.B.; Ifrim, D.C.; Saeed, S.; Jacobs, C.; van Loenhout, J.; de Jong, D.; Stunnenberg, H.G.; et al. Bacille Calmette-Guerin induces NOD2-dependent nonspecific protection from reinfection via epigenetic reprogramming of monocytes. Proc. Natl. Acad. Sci. USA 2012, 109, 17537-17542. [CrossRef]

38. Hernández-Chávez, M.J.; Pérez-García, L.A.; Niño-Vega, G.A.; Mora-Montes, H.M. Fungal Strategies to Evade the Host Immune Recognition. J. Fungi 2017, 3, 51. [CrossRef] [PubMed]

39. Arts, R.J.; Moorlag, S.J.; Novakovic, B.; Li, Y.; Wang, S.-Y.; Oosting, M.; Kumar, V.; Xavier, R.J.; Wijmenga, C.; Joosten, L.A.; et al. BCG Vaccination Protects against Experimental Viral Infection in Humans through the Induction of Cytokines Associated with Trained Immunity. Cell Host Microbe 2018, 23, 89-100. [CrossRef]

40. Netea, M.G.; Joosten, L.A.B.; Latz, E.; Mills, K.; Natoli, G.; Stunnenberg, H.G.; O’Neill, L.; Xavier, R.J. Trained immunity: A program of innate immune memory in health and disease. Science 2016, 352, aaf1098. [CrossRef] [PubMed]

41. Cheng, S.-C.; Quintin, J.; Cramer, R.A.; Shepardson, K.M.; Saeed, S.; Kumar, V.; Giamarellos-Bourboulis, E.; Martens, J.; Rao, N.A.; Aghajanirefah, A.; et al. mTOR- and HIF-1 -mediated aerobic glycolysis as metabolic basis for trained immunity. Science 2014, 345, 1250684. [CrossRef] [PubMed]

42. Wen, A.-Q.; Wang, J.; Feng, K.; Zhu, P.-F.; Wang, Z.-G.; Jiang, J.-X. Effects of haplotypes in the interleukin $1 \beta$ promoter on lipopolysaccharide-induced interleukin $1 \beta$ expression. Shock 2006, 26, 25-30. [CrossRef] [PubMed]

43. Uthayakumar, D.; Paris, S.; Chapat, L.; Freyburger, L.; Poulet, H.; De Luca, K. Non-specific Effects of Vaccines Illustrated Through the BCG Example: From Observations to Demonstrations. Front. Immunol. 2018, 9, 2869. [CrossRef] [PubMed]

44. Arts, R.J.; Carvalho, A.; La Rocca, C.; Palma, C.; Rodrigues, F.; Silvestre, R.; Kleinnijenhuis, J.; Lachmandas, E.; Gonçalves, L.G.; Belinha, A.; et al. Immunometabolic Pathways in BCG-Induced Trained Immunity. Cell Rep. 2016, 17, 2562-2571. [CrossRef]

45. Arts, R.J.W.; Blok, B.A.; Aaby, P.; Joosten, L.A.B.; De Jong, D.; Van Der Meer, J.W.M.; Benn, C.S.; Van Crevel, R.; Netea, M.G. Long-term in vitro and in vivo effects of $\gamma$-irradiated BCG on innate and adaptive immunity. J. Leukoc. Biol. 2015, 98, 995-1001. [CrossRef]

46. Arts, R.J.W.; Blok, B.A.; Van Crevel, R.; Joosten, L.A.B.; Aaby, P.; Benn, C.S.; Netea, M.G. Vitamin A induces inhibitory histone methylation modifications and down-regulates trained immunity in human monocytes. J. Leukoc. Biol. 2015, 98, 129-136. [CrossRef]

47. Kaufmann, E.; Sanz, J.; Dunn, J.L.; Khan, N.; Mendonça, L.E.; Pacis, A.; Tzelepis, F.; Pernet, E.; Dumaine, A.; Grenier, J.-C.; et al. BCG Educates Hematopoietic Stem Cells to Generate Protective Innate Immunity against Tuberculosis. Cell 2018, 172, 176-190. [CrossRef]

48. Leentjens, J.; Kox, M.; Stokman, R.; Gerretsen, J.; Diavatopoulos, D.A.; Van Crevel, R.; Rimmelzwaan, G.F.; Pickkers, P.; Netea, M.G. BCG Vaccination Enhances the Immunogenicity of Subsequent Influenza Vaccination in Healthy Volunteers: A Randomized, Placebo-Controlled Pilot Study. J. Infect. Dis. 2015, 212, 1930-1938. [CrossRef]

49. Ohrui, T.; Nakayama, K.; Fukushima, T.; Chiba, H.; Sasaki, H. Prevention of elderly pneumonia by pneumococcal, influenza and BCG vaccinations. Nihon Ronen Igakkai Zasshi. Jpn. J. Geriatr. 2005, 42, 34-36. [CrossRef] [PubMed]

50. Wardhana, D.E.; Sultana, A.; Mandang, V.V.; Jim, E. The efficacy of Bacillus Calmette-Guerin vaccinations for the prevention of acute upper respiratory tract infection in the elderly. Acta Med. Indones. 2011, 43, 185-190. 
51. Giamarellos-Bourboulis, E.J.; Tsilika, M.; Moorlag, S.; Antonakos, N.; Kotsaki, A.; Domínguez-Andrés, J.; Kyriazopoulou, E.; Gkavogianni, T.; Adami, M.-E.; Damoraki, G.; et al. Activate: Randomized Clinical Trial of BCG Vaccination against Infection in the Elderly. Cell 2020, 183, 315-323. [CrossRef] [PubMed]

52. Duggal, N.A.; Niemiro, G.; Harridge, S.D.; Simpson, R.J.; Lord, J.M. Can physical activity ameliorate immunosenescence and thereby reduce age-related multi-morbidity? Nat. Rev. Immunol. 2019, 19, 563-572. [CrossRef]

53. Metcalf, T.U.; Cubas, R.A.; Ghneim, K.; Cartwright, M.J.; Van Grevenynghe, J.; Richner, J.M.; Olagnier, D.; Wilkinson, P.A.; Cameron, M.J.; Park, B.S.; et al. Global analyses revealed age-related alterations in innate immune responses after stimulation of pathogen recognition receptors. Aging Cell 2015, 14, 421-432. [CrossRef] [PubMed]

54. Whiting, C.C.; Siebert, J.; Newman, A.M.; Du, H.-W.; Alizadeh, A.A.; Goronzy, J.; Weyand, C.M.; Krishnan, E.; Fathman, C.G.; Maecker, H.T. Large-Scale and Comprehensive Immune Profiling and Functional Analysis of Normal Human Aging. PLoS ONE 2015, 10, e0133627. [CrossRef] [PubMed]

55. Beer, L.; Zimmermann, M.; Mitterbauer, A.; Ellinger, A.; Gruber, F.; Narzt, M.-S.; Zellner, M.; Gyöngyösi, M.; Madlener, S.; Simader, E.; et al. Analysis of the Secretome of Apoptotic Peripheral Blood Mononuclear Cells: Impact of Released Proteins and Exosomes for Tissue Regeneration. Sci. Rep. 2015, 5, 16662. [CrossRef]

56. Rivas, M.N.; Ebinger, J.E.; Wu, M.; Sun, N.; Braun, J.; Sobhani, K.; Van Eyk, J.E.; Cheng, S.; Arditi, M. BCG vaccination history associates with decreased SARS-CoV-2 seroprevalence across a diverse cohort of health care workers. J. Clin. Investig. $2021,131$. [CrossRef] [PubMed] 